\title{
TINDAK KOMUNIKASI PEMBELAJARAN DI SEKOLAH DASAR
}

\author{
Wahyu Widodo \& Kardiana Metha Rozhana \\ wahyuwidodo.pgsd@unitri.ac.id,jr.kardiana@yahoo.com \\ Keperawatan \\ Fakultas Ilmu Kesehatan \\ Universitas Tribhuwana Tunggadewi Malang
}

\begin{abstract}
The objective of the study is to describe the form of learning communication in the classroom and the meaning of the students to the learning communication on verbal, non-verbal, interpersonal, group, and public communication. The research used qualitative approach with phenomenology study design. The result of the research is the expression of thoughts and feelings of students to verbal communication is easy to understand the material and dare to ask. The expression of students' thoughts and feelings toward non-verbal communication is fear when teachers speak with high intonation, but students feel happy and feel loved by the teacher's touch. Expression of thoughts and feelings of students to interpersonal communication is a feeling of fun when teachers ask news, the state of self, health, birthday celebrations, and attention when experiencing bullying. Expression of thoughts and feelings of students to group communication is a feeling of fun when learning groups, feelings of freedom to discuss and ask the task personally to the teacher and discipline when grouping students who are busy in the classroom to be advised teachers. Expression of thoughts and feelings of students to public communication is easy to understand the subject matter and feelings of pleasure when inserted humor in the lecture method.
\end{abstract}

Keywords: students' meaning, instructional communication, elementary school

\begin{abstract}
Abstrak: Tujuan penelitian ini yaitu mendeskripsikan bentuk tindak komunikasi pembelajaran di kelas dan pemaknaan siswa terhadap tindak komunikasi pembelajaran terhadap tindak komunikasi verbal, non-verbal, interpersonal, kelompok, dan publik. Penelitian menggunakan pendekatan kualitatif dengan rancangan studi fenomenologi. Hasil penelitian yaitu ungkapan pikiran dan perasaan siswa terhadap komunikasi verbal yaitu mudah memahami materi dan berani bertanya. Ungkapan pikiran dan perasaan siswa terhadap komunikasi non verbal yaitu merasa takut saat guru berbicara dengan intonasi tinggi, namun siswa merasa senang dan merasa disayangi dengan sentuhan guru. Ungkapan pikiran dan perasaan siswa terhadap komunikasi interpersonal yaitu perasaan senang saat guru menanyakan kabar, keadaan diri, kesehatan, perayaan ulang tahun, dan perhatian saat mengalami bullying. Ungkapan pikiran dan perasaan siswa terhadap komunikasi kelompok yaitu perasaan senang ketika belajar kelompok, perasaan leluasa berdiskusi dan menanyakan tugas secara pribadi kepada guru dan disiplin saat pengelompokan siswa yang suka ramai di kelas untuk dinasehati guru. Ungkapan pikiran dan perasaan siswa terhadap komunikasi publik yaitu mudah memahami materi pelajaran dan perasaan senang ketika disisipkan humor dalam metode ceramah.
\end{abstract}

Kata Kunci: pemaknaan siswa, komunikasi pembelajaran, sekolah dasar

\section{PENDAHULUAN}

Pembelajaran menyenangkan menekankan pada suasana pembelajaran yang ringan, cair, penuh keakraban, namun tetap memperhatikan kebermaknaan belajar. Penelitian Widodo (2015) menunjukkan bahwa pembelajaran menyenangkan dan 
Wahyu \& Kardiana, Tindak Komunikasi Pembelajaran di...

bermakna dapat diwujudkan dengan mengelola tindak komunikasi pembelajaran. Tindak komunikasi pembelajaran tersebut dapat berupa komunikasi verbal, komunikasi non verbal, dan penggunaan bentuk-bentuk komunikasi pembelajaran.

Hasil pengamatan awal pada pembelajaran di kelas IV SDN Percobaan 1 Malang (observasi/5/5/2017) menunjukkan bahwa pada saat awal pembelajaran, guru membuka pembelajaran dengan salam, menanyakan keadaan kesehatan siswa, dan sesekali menghampiri siswa untuk menenangkan siswa yang ramai. Guru menyentuh pundak siswa yang ramai dan menasehati dengan suara yang lembut. Ketika kegiatan presentasi hasil diskusi kelas, siswa yang ramai dibentak oleh guru sehingga siswa tersebut tertunduk dan tampak tegang. Hal ini menunjukkan bahwa guru memilih untuk membentak karena termasuk siswa "khusus". Hal itu juga menegaskan bahwa guru telah memahami karaktersitik siswa sehingga berdampak pada bentuk komunikasi pembelajaran yang dipilih.

Beberapa siswa berpendapat merasa takut dibentak guru namun juga suka ramai di kelas. Pernyataan siswa tersebut menggambarkan bahwa siswa masih mudah terpengaruh oleh perilaku temannya, apabila temannya ramai, dan ikut ramai. Namun, sebenarnya siswa tersebut merasa takut apabila dibentak oleh guru. Hal itu menunjukkan bahwa guru dapat mengelola perilaku destruktif siswa di dalam kelas dengan menggunakan tindak komunikasi pembelajaran yang sesuai.

\section{METODE}

Penelitian ini menggunakan pendekatan kualitatif dengan rancangan studi fenomenologi. Hal itu dipilih karena penelitian ini bermaksud mengungkap makna yang dihayati oleh subyek penelitian dalam kondisi alamiah. Hal itu sebagaimana Hanurawan (2012) bahwa tujuan penelitian fenomenologi adalah memahami esensi tentang pengalaman dunia terdalam individu tentang suatu fenomena berdasar perspektif individu itu sendiri. Berdasarkan pemahaman tersebut, penelitian ini bermaksud mengungkap pemaknaan siswa terhadap tindak komunikasi pembelajaran yang diterapkan guru di kelas IV SDN Percobaan 1 Malang.

\section{PEMBAHASAN}

Berdasarkan lembar observasi (observasi/ruang kelas/8/9/2017) yang digunakan pada saat proses pembelajaran diketahui bahwa guru membuka pembelajaran dengan raut wajah yang ceria berenergi dan suara yang lantang. Guru mengecek presensi dan apabila ditemui anak yang baru masuk kelas karena sakit, guru menghampirinya dan menanyakan keadaan siswa tersebut. Guru juga tampak sesekali menghampiri siswa yang ramai maupun menemui masalah. Guru menghampiri siswa yang ramai dengan raut muka yang menunjukkan marah sedangkan guru menghampiri siswa yang menemui masalah (kehilangan uang, alat tulis, dan diejek teman) dengan raut muka yang ramah. Selanjutnya pada saat kelas ramai, guru mengacungkan tangannya tanda kelas harus segera tenang kembali.

Pada saat proses belajar kelompok, tampak guru selalu keliling ke masingmasing kelompok. Guru menunjukkan gesture membungkuk, berbicara pelan, sambil memberikan contoh cara mengerjakan soal, namun apabila ada kelompok yang ramai guru menunjukkan gesture berkacak pinggang. Setelah proses belajar kelompok selesai dan masing-masing kelompok telah mempresentasikan tugasnya, selanjutnya guru 
Wahyu \& Kardiana, Tindak Komunikasi Pembelajaran di...

menjelaskan di depan kelas. Guru menjelaskan dengan memperagakan model dan suara yang lantang. Sesekali guru menyisipkan humor, tampak siswa suka humor yang bernuansa "gagal" contoh guru memperagakan bidang kemudian bidangnya jatuh, tampak siswa merespon tertawa.

Berdasarkan temuan tersebut dapat diinterpretasikan bahwa (1) guru melakukan variasi tindak komunikasi pembelajaran verbal dan non verbal; (2) guru melakukan variasi tindak komunikasi pembelajaran interpersonal, kelompok, dan publik. Data berdasarkan hasil wawancara dengan guru dapat dijelaskan seperti berikut (wawancara/guru/8/9/2017).

Peneliti : Bagaimana ibu mengaplikasikan komunikasi pembelajaran yang efektif?

Guru : menggunakan bahasa dan mengemas informasi secara jelas, sehingga mudah diterima dan dipahami oleh pendengar. penggunaan bahasa dan kebenaran informasi yang disampaikan. bahasa dan informasi harus sesuai dengan keadaan dan lingkungan dimana komunikasi itu terjadi. Bahasa dan informasi yang akan disajikan harus disusun dengan alur atau sistematika yang jelas, sehingga pihak yang menerima informasi cepat tanggap. Adanya tata krama dan etika. Ketika memasuki materi baru, guru tidak memperbolehkan siswa menaruh benda apapun di atas meja, hal ini dilakukan agar komunikasi antar guru dengan siswa dan siswa dengan siswa lebih efektif

Peneliti : Bagaimana ibu mewujudkan komunikasi interpersonal?

Guru : (saya tidak tahu pasti bagaiamana saya mengajar, hanya dapat di amati orang lain) yang jelas saya selalu berupaya ada kontak mata, mimik wajah, dan ketegasan dalam menyampaikan pelajaran

Peneliti : Bagaimana ibu mewujudkan komunikasi kelompok?

Antara guru-siswa, siswa-siswa harus ada rasa saling terbuka, memberikan kesempatan pada siswa untuk berbicara, mendengarkan keluh kesah siswa di kelas baik dalam pembelajaran maupun pribadi. Namun dalam komunikasi kelompok ada komponen yang di dalamnya terjadi komunikasi antarpersonal.

Peneliti : Bagaimana ibu mewujudkan komunikasi publik?

Mengunakan metode ceramah, pengetahuan guru yang harus memadahi

Hasil wawancara tersebut dapat diinterpretasikan bahwa guru telah memahami fungsi komunikasi efektif melalui komunikasi interpersonal, komunikasi kelompok, dan komunikasi public dalam proses pembelajaran. Hal itu berpengaruh pada terwujudnya variasi komunikasi pembelajaran di kelas. Selain itu, dengan memahami komunikasi pembelajaran, guru lebih siap baik secara pemahaman materi maupun rencana pembelajaran yang akan dilaksanakan.

Berdasarkan lembar observasi dan hasil wawancara tersebut di atas dapat ditemukan pola bahwa guru melakukan variasi komunikasi pembelajaran berikut (1) Komunikasi Verbal; (2) Komunikasi Non Verbal; (3) Komunikasi Interpersonal; (4) Komunikasi Kelompok; (5) Komunikasi Publik.

Komunikasi verbal diwujudkan dalam bentuk berbicara saat membimbing belajar kelompok dan klasikal. Komunikasi non verbal diwujudkan dalam bentuk intonasi suara yang tinggi saat pembelajaran klasikal dan untuk menertibkan kelas, sedangkan intonasi suara rendah digunakan untuk membimbing siswa pada saat belajar kelompok. Selain itu gesture dan mimic muka digunakan guru untuk mendukung pembelajaran klasikal. Komunikasi interpersonal diwujudkan dalam bentuk menanyakan kesehatan dan kabar keluarga dari siswa yang sakit, merayakan ulang tahun siswa, diskusi dengan siswa pada saat belajar kelompok. Komunikasi Kelompok diwujudkan dalam bentuk membimbing siswa pada saat belajar kelompok dan Komunikasi public diwujudkan dalam bentuk pembelajaran klasikal. 
Wahyu \& Kardiana, Tindak Komunikasi Pembelajaran di...

\section{Pemaknaan Siswa terhadap Tindak Komunikasi Pembelajaran Ungkapan pikiran dan perasaan siswa terhadap tindak komunikasi verbal}

Analisis data tentang ungkapan pikiran dan perasaan siswa terhadap tindak komunikasi verbal dijelaskan berdasarkan hasil kuesioner semi terbuka (KST) tanggal 27/9/2017 seperti berikut. Beberapa siswa (identitas siswa diinisialkan) mengungkapkan bahwa:

1) Kalau dijelaskan guru lebih jelas. Pelajarannya jadi mengerti ((KST/NW/IPT/27/9/17).

2) Lebih tau maksud pelajarannya. (KST/KL/IPT/27/9/17).

3) Lebih mudah dijelaskan oleh guru (KST/VK/IPT/27/9/17).

4) Lebih mudah dan jelas (KST/AI/IPT/27/9/17).

5) Menjadi tau yang dimaksud dalam buku (KST/AL/IPT/27/9/17).

6) Lebih mudah kalo dijelaskan dan ditulis di papan tulis (KST/ZD/IPT/27/9/17).

7) Mudah dan jelas, jadi tidak bingung (KST/ZD/IPT/27/9/17).

8) Mengerti dengan apa yang saya pelajari di buku (KST/ZD/IPT/27/9/17).

Data nomor 1-7 menunjukkan bahwa siswa merasa lebih mudah dan jelas apabila guru menjelaskan pelajaran. Apabila dikaitkan dengan hasil wawancara guru, kemudahan tersebut disebabkan oleh pemahaman guru tentang komunikasi efektif dan kesiapan materi.

Selanjutnya, analisis data tentang ungkapan pikiran siswa terhadap tindak komunikasi verbal dijelaskan berdasarkan hasil wawancara (WW) tanggal 9-18/9/2017 seperti berikut. Beberapa siswa mengungkapkan:

9) Kalau dijelaskan bu Yayuk (Ibu Guru) lebih mudah pak, jadi ngerti (WW/VK/IPT/11/9/17).

10) Lebih mudah pak, saya tidak takut bertanya (WW/EL/IPT/13/9/17).

11) Lebih mudah pak, ndak tau, pokoknya pas Ibu Yayuk menerangkan saya jd ngerti caranya (WW/AI/IPT/9/9/17).

12) Jadi lebih tahu pak, caranya mengerjakan, saya kalau ndak ngerti juga bertanya (WW/AM/IPT/18/9/17).

Data nomor 9-12 menunjukkan bahwa siswa merasa lebih mudah mempelajari materi apabila dijelaskan oleh guru. Termasuk adanya temuan siswa tidak takut untuk bertanya.

Analisis data tentang ungkapan pikiran dan perasaan siswa terhadap tindak komunikasi verbal dijelaskan berdasarkan hasil kuesioner semi terbuka (KST) tanggal 27/9/2017 seperti berikut. Beberapa siswa mengungkapkan:

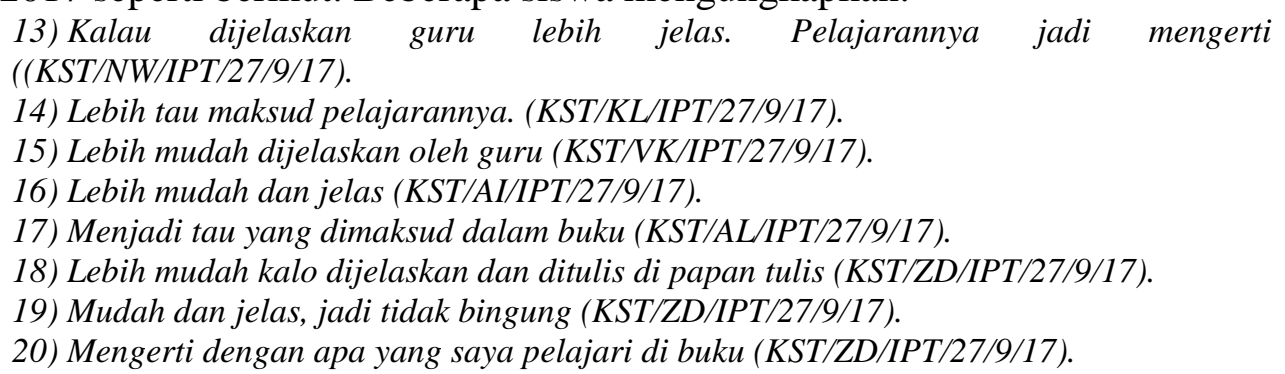

18) Lebih mudah kalo dijelaskan dan ditulis di papan tulis (KST/ZD/IPT/27/9/17).

19) Mudah dan jelas, jadi tidak bingung (KST/ZD/IPT/27/9/17).

20) Mengerti dengan apa yang saya pelajari di buku (KST/ZD/IPT/27/9/17).

Data nomor 13 - 20 menunjukkan bahwa siswa merasa lebih mudah dan jelas apabila guru menjelaskan pelajaran. Apabila dikaitkan dengan hasil wawancara guru, kemudahan tersebut disebabkan oleh pemahaman guru tentang komunikasi efektif dan kesiapan materi.

Selanjutnya, analisis data tentang ungkapan pikiran siswa terhadap tindak komunikasi verbal dijelaskan berdasarkan hasil wawancara (WW) tanggal 9-18/9/2017 seperti berikut. Beberapa siswa mengungkapkan: 
Wahyu \& Kardiana, Tindak Komunikasi Pembelajaran di...

21) Kalau dijelaskan bu Yayuk (Ibu Guru) lebih mudah pak, jadi ngerti (WW/VK/IPT/11/9/17).

22) Lebih mudah pak, saya tidak takut bertanya (WW/EL/IPT/13/9/17).

23) Lebih mudah pak, ndak tau, pokoknya pas Ibu Yayuk menerangkan saya jd ngerti caranya (WW/AI/IPT/9/9/17).

24) Jadi lebih tahu pak, caranya mengerjakan, saya kalau ndak ngerti juga bertanya (WW/AM/IPT/18/9/17).

Data nomor 9-12 menunjukkan bahwa siswa merasa lebih mudah mempelajari materi apabila dijelaskan oleh guru. Termasuk adanya temuan siswa tidak takut untuk bertanya.

Berdasarkan analisis data di atas disusun interpretasi bahwa tindak komunikasi verbal yang dilakukan guru dapat membuat siswa lebih mudah mempelajari materi. Hal itu sesuai dengan penelitian Darmadi (2015) bahwa hubungan komunikasi verbal guru dengan prestasi belajar siswa berpengaruh signifikan. Komunikasi verbal dapat berupa lisan maupun tulisan. Penggunaan komunikasi verbal guru tergantung dengan keterampilan berbicara guru. Komunikasi verbal guru dapat diketahui dari implementasi metode ceramah. Selama ini diketahui bahwa metode ceramah merupakan metode tradisional dalam pembelajaran. Metode ceramah tepat digunakan secara klasikal namun memerlukan keterampilan agar tidak membosankan siswa.

\section{Ungkapan Pikiran dan Perasaan Siswa terhadap Komunikasi Non Verbal}

Analisis data tentang ungkapan pikiran dan perasaan siswa terhadap tindak komunikasi Non verbal berkenaan dengan intonasi suara dijelaskan berdasarkan hasil kuesioner semi terbuka (KST) tanggal 27/9/2017 seperti berikut. Beberapa siswa mengungkapkan:

25) Saya takut pak kalau Ibu Yayuk suaranya keras, tapi kalu pas menjelaskan harus keras biar terdengar dari belakang ((KST/NW/IPT/27/9/17).

26) Saya merasa biasa, agar teman tidak rame (KST/KL/IPT/27/9/17).

27) Ikut merasa takut, karena teman suka rame (KST/VK/IPT/27/9/17).

28) Ikut merasa takut, ikut merasa bersalah (KST/AI/IPT/27/9/17).

29) Merasa biasa, yang penting saya tidak rame (KST/AL/IPT/27/9/17).

30) Merasa takut, karena teman suka rame (KST/ZD/IPT/27/9/17).

31) Merasa takut, saya lansung diam biar cepat selesai (KST/ZD/IPT/27/9/17).

32) Merasa takut dan diam biar cepat berubah (KST/ZD/IPT/27/9/17).

Data nomor 25- 32 menunjukkan bahwa siswa merasa takut apabila guru berbicara dengan intonasi tinggi. Apabila dikaitkan dengan hasil wawancara guru, hal tersebut dilakukan dengan tujuan agar kelas tertib kembali.

Selanjutnya, analisis data tentang ungkapan pikiran dan perasaan siswa terhadap tindak komunikasi verbal berkenaan dengan intonasi suara dijelaskan berdasarkan hasil wawancara (WW) tanggal 9-18/9/2017 seperti berikut. Beberapa siswa mengungkapkan:

33) Takut pak kalau marah, nadanya tinggi, pas menjelaskan harus keras biar terdengar jelas, ibu guru baik pak, teman yang rame (WW/VK/IPT/11/9/17).

34) Biasa pak, yang penting saya ndak rame, itu karena teman rame, ibu guru baik, jadi jelas kalau menjelaskan (WW/EL/IPT/13/9/17).

35) Ikut takut pak, ikut merasa bersalah, teman menggoda jadi ikut rame, tapi saya ndak takut kalau bertanya, ibu guru baik (WW/AI/IPT/9/9/17).

36) Takut pak, karena tadi teman rame, tidak bisa konsentrasi, tidak takut kalau bertanya kepadda guru (WW/AM/IPT/18/9/17).

Data nomor 33-36 menunjukkan bahwa siswa merasa takut dan diam apabila intonasi suara guru tinggi. Hal itu terjadi pada saat guru menertibkan kelas yang ramai. 
Wahyu \& Kardiana, Tindak Komunikasi Pembelajaran di...

Selajutnya, Analisis data tentang ungkapan pikiran dan perasaan siswa terhadap tindak komunikasi Non verbal berkenaan dengan sentuhan guru dijelaskan berdasarkan hasil kuesioner semi terbuka (KST) tanggal 27/9/2017 seperti berikut. Beberapa siswa mengungkapkan:

37) Merasa tenang ((KST/NW/IPT/27/9/17).

38) Merasa tenang (KST/KL/IPT/27/9/17).

39) Kaget dan tenang (KST/VK/IPT/27/9/17).

40) Merasa tenang (KST/AI/IPT/27/9/17).

41) Biasa dan tenang (KST/AL/IPT/27/9/17).

42) Merasa tenang (KST/ZD/IPT/27/9/17).

43) Tidak takut (KST/ZD/IPT/27/9/17).

44) Merasa disayangi (KST/ZD/IPT/27/9/17).

Data nomor 37- 44 menunjukkan bahwa siswa merasa tenang dan disayangi apabila guru memberikan sentuhan kepada siswa. Apabila dikaitkan dengan hasil wawancara guru, hal tersebut dilakukan dengan tujuan agar siswa merasa diperhatikan dan tidak takut dengan guru.

Selanjutnya, analisis data tentang ungkapan pikiran dan perasaan siswa terhadap tindak komunikasi verbal berkenaan dengan sentuhan guru dijelaskan berdasarkan hasil wawancara (WW) tanggal 9-18/9/2017 seperti berikut.

45) Biasa dan tenang pak, saya suka kalau Ibu guru datang ke kelompok (WW/VK/IPT/11/9/17).

46) Tidak takut, merasa tenang pak, merasa disayangi (WW/EL/IPT/13/9/17).

47) Takut pak, hehe .. pas saya rame, saya diam pak, (WW/AI/IPT/9/9/17).

48) Waktu pulpen saya diambbil teman, saya merasa kayak ada yang membela saya pak

(WW/AM/IPT/18/9/17).

Data nomor 45-48 menunjukkan bahwa siswa merasa tenang dan disayangi dengan sentuhan guru. Siswa juga merasa aman dengan sentuhan guru. Namun, ada siswa yang merasa takut dengan sentuhan guru pada saat dia ramai di kelas.

Selajutnya, Analisis data tentang ungkapan pikiran dan perasaan siswa terhadap tindak komunikasi Non verbal berkenaan dengan mimic dan gesture dijelaskan berdasarkan hasil kuesioner semi terbuka (KST) tanggal 27/9/2017 seperti berikut. Beberapa siswa mengungkapkan:

49) Benar, sering memperagakan, lucu ((KST/NW/IPT/27/9/17).

50) Benar, diperagakan oleh guru, jadi mengerti (KST/KL/IPT/27/9/17).

51) Iya, diperagakan oleh guru, tambah mengerti (KST/VK/IPT/27/9/17).

52) Benar, Ibu guru mencontohkan dengan tangan, kalau marah wajah Ibu guru takut

(KST/AI/IPT/27/9/17).

53) Benar, Ibu guru bergerak untuk menjelaskan, pas melucu wajah Ibu guru lucu

(KST/AL/IPT/27/9/17).

54) Benar, Ibu guru memberi contoh di depan kelas (KST/ZD/IPT/27/9/17).

55) Benar, Ibu guru memberi contoh, jadi lebih jelas (KST/ZD/IPT/27/9/17).

56) Benar, ibu guru mencontohkan dengan gerak di depan kelas (KST/ZD/IPT/27/9/17).

Data nomor 49 - 56 menunjukkan bahwa siswa memahami materi dengan peragaan. Namun, bagi siswa yang ramai di kelas, gesture dan mimik wajah guru seperti mengacungkan tangan, menunjuk, dan ekspresi tidak suka membuat siswa merasa takut.

Selanjutnya, analisis data tentang ungkapan pikiran dan perasaan siswa terhadap tindak komunikasi verbal berkenaan dengan mimik dan gesture guru dijelaskan berdasarkan hasil wawancara (WW) tanggal 9-18/9/2017 seperti berikut. Beberapa siswa mengungkapkan: 
Wahyu \& Kardiana, Tindak Komunikasi Pembelajaran di...

57) Peragaan ibu yayuk lebih jelas, membuat lucu, kelas jadi rame (WW/VK/IPT/11/9/17).

58) Tambah paham, lucu pak, seperti kemarin Ibu yayuk jadi orang jualan di pasar (WW/EL/IPT/13/9/17).

59) Pas ditunjuk guru merasa takut pak, karena saya rame, kalau diajak peragaan saya tidak takut (WW/AI/IPT/9/9/17).

60) Jadi lebih mudah saja pak, pas Ibu yayuk memperagakan aliran darah pak ingat saya, saya dan teman-teman juga diajak ke depan untuk jadi darah, jadi lucu pak, ibu yayuk lucu, wajahnya pas mencontohkan lucu (WW/AM/IPT/18/9/17).

Data nomor 57 - 60 menunjukkan bahwa siswa merasa lebih memahami materi apabila dijelaskan oleh guru dengan peragaan. Siswa juga merasa senang apabila dilibatkan dalam peragaan tersebut. Namun, bagi siswa yang ramai di kelas, gesture menunjuk membuat siswa merasa takut.

Berdasarkan analisis data di atas dapat disusun interpretasi bahwa tindak komunikasi non verbal yang dilakukan guru dapat membuat siswa lebih mudah memahami materi dan merasa senang dikarenakan peragaan yang sifatnya lucu. gestur tubuh guru juga dapat membuat takut siswa seperti gesture menunjuk. Hal itu sesuai dengan penelitian Sitompul (2012) bahwa ekspresi wajah guru dapat membuat suasana pembelajaran lebih nyaman. Siswa merasa lega dan mendorong siswa untuk aktif dalam kegiatan pembelajaran.

\section{Ungkapan Pikiran dan Perasaan Siswa terhadap Komunikasi Interpersonal}

Analisis data tentang ungkapan pikiran dan perasaan siswa terhadap tindak komunikasi interpersonal dijelaskan berdasarkan hasil kuesioner semi terbuka (KST) tanggal 27/9/2017 seperti berikut. Beberapa siswa mengungkapkan:

61) Pernah, saat saya sakit kemudian masuk kelas, saya ditanyai Ibu Yayuk ((KST/NW/IPT/27/9/17).

62) Pernah, saat saya tidak masuk, Ibu Yayuk menghubungi orang tua (KST/KL/IPT/27/9/17).

63) Pernah, menanyakan kabar Ibu saya yang sakit (KST/VK/IPT/27/9/17).

64) Pernah, saat saya ikut lomba menggambar, saya ditanyai sama Ibu Yayuk (KST/AI/IPT/27/9/17).

65) Pernah, saat saya tidak masuk karena acara keluarga (KST/AL/IPT/27/9/17).

66) Pernah, saat saya sakit, Ibu Yayuk sms Ibu Saya (KST/ZD/IPT/27/9/17).

67) Pernah, saat saya ulang tahun, saya rayakan di kelas bersama Ibu Guru (KST/ZD/IPT/27/9/17).

68) Pernah, saat saya diejek teman, Ibu yayuk mendatangi saya dan bertanya-tanya (KST/ZD/IPT/27/9/17).

Data nomor 49 - 56 menunjukkan bahwa siswa pernah mengalami komunikasi interpersonal guru seperti menanyakan kabar, menanyakan keadaan diri, merayakan ulang tahun, dan memberi perhatian kepada siswa yang mengalami perilaku bullying dari teman sebaya.

Selanjutnya, analisis data tentang ungkapan pikiran dan perasaan siswa terhadap tindak komunikasi interpersonal dijelaskan berdasarkan hasil wawancara (WW) tanggal 9-18/9/2017 seperti berikut. Beberapa siswa mengungkapkan:

69) Pernah pak, saat saya sakit, merasa diperhatikan pak, ibu Yayuk memang baik orangnya, orang tua saya juga kenal (WW/VK/IPT/11/9/17).

70) Pernah pak, saat saya ada acara keluarga, saya ditanya bagiamana acaranya lancar apa tidak, saya merasa senang pak, bisa bercerita saat ada acara keluarga yang menyenangkan, saya cerita jadi cantrik saat pernikahan mas saya pak. (WW/EL/IPT/13/9/17). 
Wahyu \& Kardiana, Tindak Komunikasi Pembelajaran di...

71) Pernah pak, saya jadi takut berbohong, hehe .. karena biasanya telepon ibu saya pak, hehe .. (WW/AI/IPT/9/9/17).

72) Pernah pak, saat hari ulang tahun, hehe .. malu pak, seneng sih pak, tapi malu juga, senangnya merasa diperhatikan, Ibu Yayuk baik pak (WW/AM/IPT/18/9/17).

Data nomor 69 - 72 menunjukkan siswa merasa lebih diperhatikan dan disayangi ketika guru menjalin komunikasi yang lebih bersifat pribadi dengan siswa. Namun, bagi sebagian siswa, komunikasi yang lebih bersifat pribadi membuat siswa takut untuk berbohong karena merasa diawasi. Hal itu dapat dikatakan bahwa komunikasi interpersonal dapat meningkatkan kedisiplinan siswa.

Blandhol (2012) mendefinisikan komunikasi interpersonal sebagai proses berbagi informasi, makna dan perasaan di antara orang-orang yang berkomunikasi melalui pertukaran pesan verbal dan non verbal. Dengan demikian dapat dipahami bahwa komunikasi interpersonal dapat dibangun antara siswa dan guru secara terusmenerus dengan menekankan pada rasa kebersamaan atas upaya mencapai tujuan pembelajaran. Zeky (2009) menambahkan bahwa siswa-siswa ternyata menghayati setiap bentuk komunikasi pembelajaran yang dilakukan oleh guru seperti kontak mata, mimic, dan gesture tubuh. Komunikasi interpersonal dapat mempererat relasi siswaguru.

\section{Ungkapan Pikiran dan Perasaan Siswa terhadap Komunikasi Kelompok}

Selanjutnya, Analisis data tentang ungkapan pikiran dan perasaan siswa terhadap tindak komunikasi kelompok dijelaskan berdasarkan hasil kuesioner semi terbuka (KST) tanggal 27/9/2017 seperti berikut. Beberapa siswa mengungkapkan:

73) Pernah, sering belajar kelompok (KST/NW/IPT/27/9/17).

74) Pernah belajar kelompok (KST/KL/IPT/27/9/17).

75) Setiap hari belajar kelompok (KST/VK/IPT/27/9/17).

76) Pernah belajar kelompok (KST/AI/IPT/27/9/17).

77) Pernah, setiap hari belajar kelompok (KST/AL/IPT/27/9/17).

78) Pernah, setiap hari belajar kelompok (KST/ZD/IPT/27/9/17).

79) Pernah, saya suka belajar kelompok (KST/ZD/IPT/27/9/17).

80) Pernah (KST/ZD/IPT/27/9/17).

Data nomor 73 - 80 menunjukkan bahwa siswa selalu belajar kelompok setiap hari. Siswa merasa senang belajar kelompok. Belajar kelompok menjadi salah satu bentuk komunikasi kelompok yang diterapkan oleh guru.

Selanjutnya, analisis data tentang ungkapan pikiran dan perasaan siswa terhadap tindak komunikasi kelompok dijelaskan berdasarkan hasil wawancara (WW) tanggal 918/9/2017 seperti berikut. Beberapa siswa mengungkapkan:

81) Pernah pak, saya suka belajar kelompok, lebih santai pak, ibu yayuk juga menjelaska ke masing-masing kelompok (WW/VK/IPT/11/9/17).

82) Pernah pak, setiap hari belajar kelompok kok pak, ya senang saja, bisa bergaul sama teman. Ibu yayuk juga mendampingi dan membimbing pak, jalanjalan ke kelompokkelompok (WW/EL/IPT/13/9/17).

83) Pernah pak, ibu yayuk pasti keliling melihat tugas kelompok, kalau rame ndak boleh sama ibu yayuk, tapi kalau ramenya diskusi boleh pak, yang ramen anti saya bu yayuk dikumpulkan pak, dinasehati, saya senang belajar kelompok pak. Saya ndak suka dinasehati, Saya juga bisa bertanya pak, saya malu kalau bertanya pas ibu di kelas, iya pak, kalau kelompok saya lebih berani, hehe .. (WW/AI/IPT/9/9/17).

84) Pernah pak, lebih santai pak, ibu yayuk juga mau datang kalau dimintai tolong menjelaskan tugas. Lebih enak kelompok pak, lebih bebas bertanya ke Ibu Yayuk pas Ibu datang ke kelompok (WW/AM/IPT/18/9/17). 
Wahyu \& Kardiana, Tindak Komunikasi Pembelajaran di...

Data nomor 57 - 60 menunjukkan bahwa siswa merasa lebih santai dan terlihat akrab baik sesama siswa maupun dengan guru. Guru tidak merasa keberatan untuk datang ke kelompok yang memerlukan penjelasan lebih lanjut dan hal tersebut ternyata membuat siswa tidak malu bertanya sesuai tingkat kesulitan masing-masing.

Selain komunikasi interpersonal, guru juga perlu menguasai komunikasi kelompok. Hal itu berdasarkan pada kenyataan bahwa keberhasilan pembelajaran tidak hanya bergantung pada relasi siswa dan guru namun juga relasi antar siswa dan guru (berkelompok). Iriantara (2014) menjelaskan bahwa komunikasi kelompok lebih menekankan pada pengembangan pola interaksi antar anggota kelompok agar terjadi diskusi kelompok yang bersifat konstruktif.

\section{Ungkapan Pikiran dan Perasaan Siswa terhadap Komunikasi Publik}

Berikut hasil kuesioner semi terbuka (KST) tanggal 27/9/2017 analisis data tindak komunikasi Publik:

85) Ibu Yayuk pernah menggunakan metode ceramah, kalau sebentar paham, kalau lama jadi bingung ((KST/NW/IPT/27/9/17).

86) Pernah menggunakan metode ceramah, lebih jelas apabila ada contoh peragaan (KST/KL/IPT/27/9/17).

87) Pernah menggunakan metode ceramah, lebih mudah memahami (KST/VK/IPT/27/9/17).

88) Pernah menggunakan metode ceramah, tidak suka karena harus diam, (KST/AI/IPT/27/9/17).

89) Pernah menggunakan metode ceramah, lebih mudah paham (KST/AL/IPT/27/9/17).

90) Pernah menggunakan metode ceramah, lebih mudah memahami, ada contoh dan diperagakan guru (KST/ZD/IPT/27/9/17).

91) Pernah menggunakan metode ceramah, kalau ceramah Ibu Yayuk suka melucu (KST/ZD/IPT/27/9/17).

92) Pernah menggunakan metode ceramah, kalau ceramah suka, lucu (KST/ZD/IPT/27/9/17).

Data nomor 85 - 92 menunjukkan bahwa siswa merasa lebih memahami materi apabila dijelaskan oleh guru dengan peragaan. Siswa merasa tertarik apabila dalam metode ceramah diselingi humor. Namun, bagi siswa yang suka ramai di kelas, metode ceramah terasa membosankan.

Selanjutnya, analisis data tentang ungkapan pikiran dan perasaan siswa terhadap tindak komunikasi publik dijelaskan berdasarkan hasil wawancara (WW) tanggal 918/9/2017 seperti berikut.

93) Pas ceramah ibu yayuk suka melucu, jelas pak penjelasan dari Ibu Yayuk, (WW/VK/IPT/11/9/17).

94) sewaktu ceramah bisa memperhatikan pak, benar pak, ada peragaan, lebih cepet paham maksudnya kayak gitu (WW/EL/IPT/13/9/17).

95) Pas ceramah harus diam pak, kurang suka, enak belajar kelompok pak, lucu pak, pas memerankan ibu-ibu jualan di pasar (WW/AI/IPT/9/9/17).

96) Ceramah Ibu yayuk bagus pak, bisa lebih paham aripda dijelaskan teman (WW/AM/IPT/18/9/17).

Data nomor 93 - 96 menunjukkan bahwa siswa merasa memahami materi apabila dijelaskan oleh guru dengan metode ceramah dan peragaan dengan sisipan humor secara verbal maupun non verbal sehingga siswa merasa senang. Namun, bagi siswa yang suka ramai di kelas, komunikasi public dalam bentuk ceramah membuat bosan.

Iriantara (2014) menyebutkan komunikasi publik merupakan salah satu bentuk komunikasi yang terpusat pada komunikator. Pembelajaran yang menggunakan metode 
Wahyu \& Kardiana, Tindak Komunikasi Pembelajaran di...

ceramah pada dasarnya merupakan salah satu bentuk komunikasi public yang sering diidentikkan dengan dominannya peran guru. Ceramah yang disampaikan pembicara, baik guru maupun siswa yang sedang melakukan presentasi di depan kelas, seperti yang dikemukakan Richmond dalam Iriantara (2014) perlu memperhatikan beberapa hal seperti berikut: (1) memiliki pengetahuan yang memadai untuk bisa menjelaskan topic yang dibahas dengan bahasa yang mudah dipahami; (2) bahan ceramah disampaikan dengan organisasi yang rapi; (3) komunikator mampu menarik dan menjaga perhatian khalayak; (4) bahan ceramah dipilih sesuai nilai daya tariknya; (5) komunikator menunjukkan diri sebagai orang yang kompeten dan antusias dalam berkomunikasi; (6) komunikator bisa memperlihatkan dirinya memiliki sense of humor.

\section{SIMPULAN}

Berdasarkan paparan hasil analisis data dan temuan penelitian serta pembahasan disimpulkan bahwa tindak komunikasi pembelajaran yang dilakukan guru saat pembelajaran di kelas diwujudkan dalam bentuk (1) komunikasi verbal; (2) komunikasi non verbal; (3) komunikasi interpersonal; (4) komunikasi kelompok; dan (5) komunikasi publik.

\section{DAFTAR PUSTAKA}

Blandhol, S. 2012. Teaching Interpersonal Communication Skills Using an Internet Based Intervention: a Randomised Controlled Trial. Tesis. Oslo: University of Oslo, (Online), (Online), (https://www.duo.uio.no/handle/10852/18207), diakses 1 Juni 2016

Darmadi, D. 2015. Hubungan Komunikasi Guru terhadap Prestasi Belajar Siswa pada Mata Pelajaran Sosiologi di SMU Negeri 5 Samarinda, dalam jurnal eJournal Ilmu Komunikasi, 3(3) 211-225

Hanurawan, F. 2012. Metode Penelitian Kualitatif dalam Ilmu Psikologi. Surabaya: Pusat Studi Peningkatan Kinerja Masyarakat LPPM Universitas Airlangga Kampus C.

Iriantara, Yosal. 2014. Komunikasi Pembelajaran Interaksi, Komunikatif dan Edukatif dalam Kelas. Bandung: PT Simbiosa Rekatama Media

Sitompul, N. C. 2012. Perilaku Komunikasi Non Verbal Guru dalam Kelas Pembelajaran: Maknanya bagi Siswa SMA, dalam Jurnal Jurnal Pendidikan dan Pembelajaran, 19 (1) 38-49

Widodo, W. 2016. Wujud Kenyamanan Belajar Siswa, Pembelajaran Menyenangkan, dan Pembelajaran Bermakna di Sekolah Dasar, dalam Jurnal Ar-Risalah, XVIII(2) 22-37

Zeky, C. P. (2009). The importance of non-verbal communication in classroom management, dalam jurnal Procedia-Social and Behavioral Sciences, 1(1), 14431449 ,

(Online), (http://www.sciencedirect.com/science/article/pii/S1877042809002572), diakses 1 Juni 2016. 